\title{
DOENÇAS DEBILITANTES E A SEXUALIDADE DO CASAL
}

Rosenilda Moura da Silva ${ }^{1}$; Maria Alexina Ribeiro ${ }^{2}$

\section{DEBILITATING ILLNESSES AND THE SEXUALITY OF THE COUPLE}

Resumo: O objetivo desse estudo é conhecer a repercussão do câncer no relacionamento conjugal e na vida sexual do casal em pacientes sob cuidados paliativos. Apresentamos um estudo de caso cuja amostra foi formada por um casal residente no Distrito Federal, dos quais um dos cônjuges esteve internado no Hospital de Apoio de Brasília (HAB). O estudo privilegiou a análise qualitativa, foi utilizado o método clínico e os dados foram interpretados de acordo com a abordagem sistêmica da família e teóricos da sexualidade humana. Os instrumentos utilizados foram: roteiro de entrevista semiestruturada, genograma familiar e técnica de colagem. Os dados apontam para a reestruturação familiar e conjugal e para os aspectos sócio-culturais que permeam a atitude e comportamento sexual dos participantes. $\mathrm{O}$ método utilizado mostrou-se adequado para se atingir os objetivos e para melhor compreensão do fenômeno estudado. Os dados foram discutidos e relacionados aos trabalhos constantes no levantamento bibliográfico.

Palavras-chave: Sexualidade; câncer; cuidados paliativos; casal; família.

Abstract: The aim of this research is to study the repercussion of cancer on marriage relationship and in the couple's sexual life in patients under palliative care. We present a study of case whose sample was formed by a resident couple in the Distrito Federal", of which one of the spouses was interned in the "Hospital de Apoio de Brasília (HAB)". The research privileged the qualitative analysis, the clinical method was used and the data had been interpreted according the family systemic approach as well as theoretical

\footnotetext{
Mestre em Psicologia pela Universidade Católica de Brasília.e-mail: rosems@linkexpress.com.br
}

2 Professora Doutora da Universidade Católica de Brasília. e-mail: alexina @solar.com.br 
studies of human sexuality. The methods used were: semi structured guided interview, family genogram and a collage technique. The data pointed to a family and conjugal restructuration and social-cultural aspects reflected through the attitude and sexual behavior of the parts. The method was appropriate to accomplish the previously outlined objectives and for better better comprehension of the phenomenon under study. The data were discussed and related to works inserted at the bibliographic review

Keywords: Sexuality; cancer; palliative care; couple; family.

\section{Introdução}

Os pesquisadores da sexualidade humana têm se preocupado em estudar a resposta sexual de indivíduos que apresentam certo nível de saúde geral (KAPLAN, 1974, 1978, 1983; MASTERS; JOHNSON, 1976; HITE, 1982, 1991; KINSEY, POMEROY, MARTIN, 1948, 1953). Quando se relaciona doença e sexualidade, geralmente são enfocadas as doenças sexualmente transmissíveis - DST e as disfunções sexuais (MASTERS, JOHNSON, 1979, 1988; CAVALCANTI, CAVALCANTI, 1992) como conseqüência do impacto de algumas doenças crônicas (KAPLAN, 1974; KOLODNY, MASTERS, JOHNSON, 1982; KUSNETZOFF, 1987, 1988).

Encontramos pesquisas que relacionam câncer e sexualidade: Tang, Siu, Lai, e Chung (1996) abordam o ajustamento sexual de mulheres chinesas depois do câncer ginecológico segundo as crenças culturais na sociedade chinesa contemporânea; Swift (1998) e Mulley (1998) afirmam que as sobreviventes de câncer de mama querem discutir seus problemas de sexo com especialista de sexualidade; Bourgeois-Law e Lotocki (1999) chamam a atenção para os efeitos do tratamento do câncer ginecológico na sexualidade; Lee, Zelefsky, Mckee e Leibel (1999) estudam a eficácia do sildenafil oral nos pacientes com disfunção erétil após a radioterapia para o carcinoma da próstata; Clarke (2002) apresenta a sexualidade sob o enfoque do envelhecimento, relacionando câncer de próstata com níveis de ereção peniana; Duarte e Andrade (2003) investigam a percepção de mulheres mastectomizadas quanto à sua sexualidade, mostrando que apesar dos temores, algumas mulheres produziram diversos modos de (re)significarem e expressarem sua sexualidade. Esses estudos relacionam sexualidade e câncer sem, contudo, fazer alusão aos cuidados paliativos, além de enfocarem apenas aspectos individuais. 
Os cuidados paliativos (PESSINI, 2004) só foram reconhecidos pela comunidade médica e de saúde a partir de 1990, ano em que a Organização Mundial de Saúde (OMS) definiu esses cuidados como "o cuidado ativo e total dos pacientes cuja enfermidade não responde mais aos tratamentos curativos" (MCCOUGHLAN, 2004, p. 169). Os estudos sobre os cuidados paliativos parecem estar mais voltados ao contexto hospitalar: Payne, Large, Jarrett e Turner, (2000) analisam a legibilidade, a qualidade e o tipo das informaçōes contidas em folhetos dados aos pacientes e famílias em unidades de cuidados paliativos; Simoni e Santos (2003) apresentam uma abordagem plural sobre o processo do trabalho de enfermagem; Pantilat (2004) aponta para a importância dos cuidados paliativos para os pacientes de parada cardíaca e seus familiares; Casarett (2005) trata do improvável impacto acerca de questôes familiares sobre cuidados paliativos como causadoras de angústia em pacientes quando o assunto é a morte.

Contextualizamos nosso estudo no modelo neoparadigmático da abordagem sistêmica do casal e da família (VASCONCELLOS, 1995), que leva em consideração a complexidade (MORIN, 1990) e a intersubjetividade do fenômeno observado. Entendemos que essa abordagem é apropriada para uma melhor compreensão da repercussão de uma doença debilitante nas relações conjugais e familiares (BROWN, 2001; ROLLAND, 2001). Enfocamos o ciclo de vida familiar (CARTER, MCGOLDRICK, 2001; CERVENY, 2002), o sistema emocional da família nuclear (FÉRES-CARNEIRO, 1992), a dinâmica do casal (ANDOLFI, ÂNGELO, SACCU, 1995; BUCHER, 1999; OSORIO, VALLE, 2002; SATIR, 1995; PAPP, 1995; MINUCHIN, FISHMAN, 1990) e a comunicação conjugal e familiar (WATZLAWICK, 2000).

A partir do levantamento bibliográfico, identificamos a necessidade de aprofundamento de pesquisas em Psicologia com interesse na conjugalidade e sexualidade do casal que está vivenciando uma doença debilitante (SILVA, 2007). Nesse sentido, o nosso objetivo é conhecer a repercussão que o câncer tem sobre o relacionamento conjugal e a vida sexual do casal em que um dos cônjuges esteja sob condiçōes dos cuidados paliativos, identificando: a fase do ciclo de vida que o casal está vivenciando; algumas dimensões do relacionamento conjugal que facilitam e as que dificultam a adaptação do casal frente às novas condições de vida e conhecer a avaliação que os cônjuges fazem do relacionamento conjugal atual e, especificamente a dimensão da sexualidade. Acreditamos que os dados aqui apresentados representam uma contribuição importante para as equipes de saúde, pacientes, familiares e sociedade quanto às doenças debilitantes e a sexualidade. Esclarecemos que todos os nomes dos membros da família deste estudo são fictícios. 


\section{Método}

No presente estudo, privilegiamos a metodologia qualitativa (GONZALES REY, 2005; TURATO, 2003), considerando que o conhecimento é produzido numa interação dinâmica entre o sujeito e o objeto do conhecimento, havendo um vínculo inseparável entre o mundo objetivo e intersubjetivo dos sujeitos envolvidos na pesquisa. Realizamos estudo de caso (YIN, 2001) com um casal heterossexual cuja esposa encontrava-se sob cuidados paliativos oncológicos no Hospital de Apoio de Brasília - HAB. O Hospital pertence à Secretaria de Saúde do Distrito Federal, que possui especialidade em OncoHematologia Pediátrica, Fisioterapia e Cuidados Paliativos, estando ligado à Rede de Combate ao Câncer do Distrito Federal, que foi criada para atender às necessidades de melhoramento de ações de assistência em radioterapia, cuidados paliativos e tratamento de dor oncológica, prevenção e diagnóstico precoce, sistema de registro e cirurgias oncológicas.

O casal estudado é formado por Ivonete, 53 anos, servidora pública aposentada, formada em direito e Carlos, 54 anos, comerciante, possui o segundo grau completo. A renda familiar é de catorze salários mínimos. Ivonete e Carlos são casados há 30 anos, são católicos, naturais do estado do Piauí e residem em uma cidade satélite do Distrito Federal. O casal tem três filhos, como mostra o genograma familiar (Figura 1). O diagnóstico de Ivonete é câncer de mama com metástases pulmonares. Seu recebimento ocorrera há três anos, quando realizou mastectomia em uma das mamas. Ela foi internada no HAB em 15 de maio de 2006, apresentava estado neurológico consciente e um "perfomance status" igual a PS 3. Atualmente, faz uso de morfina, insulina e Lasix, é diabética e tem hipertensão arterial. Já realizou sessões de quimioterapia e radioterapia, antes de ser internada no HAB.

Como instrumentos para levantamento dos dados, utilizamos um roteiro de entrevista semi-estruturada para esse fim (GONZALES REY, 2005), o genograma familiar (MCGOLDRICK, GERSON, 2001) e a técnica de colagem (CERQUEIRA, 2004; LIMA, 2005).

Os procedimentos para a realização do estudo foram: pedido de aprovação da realização da pesquisa junto ao Comitê de Ética em Pesquisa da Secretaria de Estado de Saúde do Distrito Federal - CEP - SES/DF; identificação dos participantes através dos prontuários; convite do casal para participação do estudo e assinatura do Termo de Consentimento Livre e Esclarecido; realização de três encontros com duração média de noventa minutos cada, na residência do casal (a esposa havia recebido alta temporária). Os dados 
foram levantados através do método clínico e interpretados de acordo com o referencial teórico da abordagem sistêmica da família e da terapia sexual, conforme o levantamento bibliográfico realizado nesse estudo.

Figura 1: SILVA, R. M. Genograma familiar do casal. 2007.

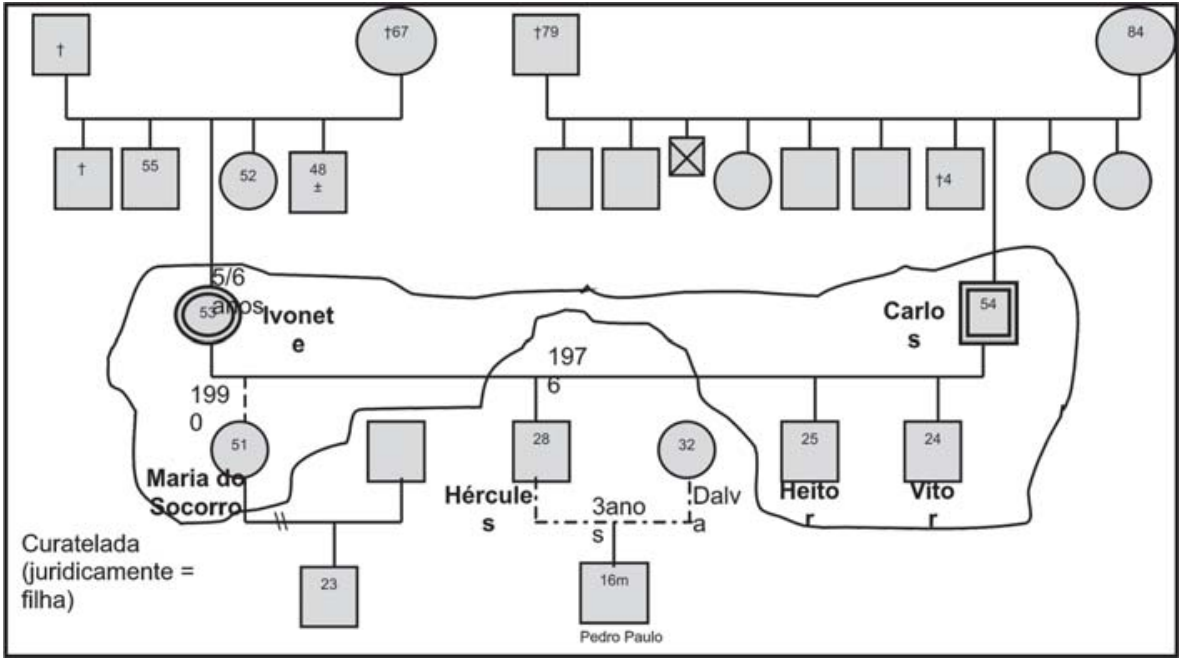

Legenda:

Participantes da pesquisa

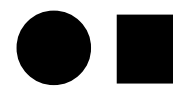

Casamento

Homem

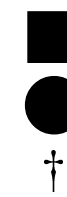

Filho biológico

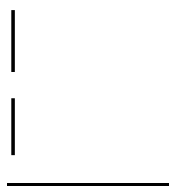

Falecimento

$\dagger$

Filho adotivo

União estável

Idade aproximada

$48 \pm$

Separação

11

Natimorto

$\mathrm{X}$

Pessoas que convivem juntas

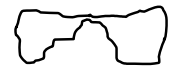

\section{Estudo de Caso}

Ivonete e Carlos estão casados há trinta anos e afirmam que sempre tiveram "um relacionamento muito sincero", onde ele se diz "muito fiel" à esposa e avalia a vida conjugal como sendo "bem aberta". No entanto, Carlos não foi sempre fiel à Ivonete. Hoje, ele afirma que não tem "coragem de trair" por causa das dificuldades enfrentadas pela esposa. Ivonete relacionou o comportamento do marido com o comportamento do seu pai biológico e contou-nos que o pai de Carlos também não era "tão fiel". 
O casal tem três filhos que moram com a família, dois solteiros e uma filha "de criação" (curatelada), que tem "problema de esquizofrenia”. Carlos afirma que "jamais” falou com eles sobre sexo, mas foram orientados a serem íntegros, honestos e tementes a Deus e ao pai. Hoje Carlos diz não bater mais nos filhos e atribuiu sua atitude ao ensinamento recebido de seus ascendentes. Ivonete acredita que sua "preocupação" com a educação dos filhos pode ter "desencadeado" a doença, uma vez que o marido sempre esteve "muito ocupado" com o seu trabalho e estudo. Ela cuidou dos filhos praticamente sozinha, da infância à adolescência. Segundo ela, outros estressores foram a perda dos pais de criação e a ida da "irmã-filha" para a família.

Ivonete recebeu o diagnóstico da doença há três anos, ocasião em que trocou de médico e foi encaminhada a um mastologista. Com a doença, Carlos assumiu o papel de "cuidador" da esposa e da família e deixou de trabalhar "para ficar à disposição dela”. Apesar da preocupação com a vida conjugal e sexual, o amor do casal fez com que Ivonete não "fraquejasse", embora tenha pensado que o esposo não mais a "olharia como mulher". Sente-se "paparicada", principalmente por ele, embora não queira deixar de fazer as compras de supermercado, porque acredita que "é seu papel”. Para ela, os cuidados do marido dificultaram a vida do casal, pois sua autonomia é muito importante porque não quer "ficar totalmente dependente". Carlos acredita que com a doença sua tensão tenha se agravado, principalmente pelo fato de esperar a esposa por um longo período de tempo. Ivonete tem percebido que o marido está preocupado com ela. Carlos não considera que a doença seja "um impedimento" para o "relacionamento normal" do casal. A participação da família nos cuidados com Ivonete é "muito boa”, segundo ela, pois todos são muito unidos.

Antes do recebimento do diagnóstico o casal considerava seu relacionamento sexual "calmo". Ivonete "ficava preocupada" com a "presença de outras pessoas" da família, como os filhos e a filha adotiva. No princípio, eles mantinham relaçōes sexuais "quase diárias" e consideravam o sexo "muito bom". Contudo, havia uma reserva ao revelar o seu corpo para o esposo. Todas as fases da resposta sexual estiveram presentes em Carlos e ainda hoje é assim. Ivonete tinha desejo sexual e continua tendo, apesar do comportamento sexual ser pautado na educação rigorosa que recebeu dos pais. O casal afirma nunca ter dormido em camas separadas.

Com a doença, as relações sexuais passaram a ser realizadas com "delicadeza" e "cuidados", havendo alteração quanto à posição utilizada. Carlos passou a ter uma resposta rápida, para "não incomodar", pois considera que o ato sexual seja "cansativo" para a esposa. Hoje, ele não espera que Ivonete atinja 
o orgasmo e pensa que a esposa só mantém relações com ele "pelo fato de cumprir a obrigação" ou "agradá-lo".

A diminuição do desejo sexual de Ivonete durou um ano, tempo que levou para se adaptar e voltar a olhar para o próprio corpo após a mastectomia. Hoje, sente-se "bem à vontade" com o desejo e excitação sexual. Às vezes, "fingia" que tinha desejo para sentir-se mais à vontade, apesar de acreditar que tenha aumentado com a chegada da doença. A menopausa e o diagnóstico interferiram na excitação sexual, sendo que a primeira causou mais impacto do que o segundo. A existência do desejo ocorre "em função da confiança" e por isso "aceita” a relação sexual. Às vezes, Ivonete mantém relações sexuais mesmo que no início não esteja "com vontade". Houve uma diminuição na intensidade e ocorrência da excitação e do orgasmo em Ivonete e o relaxamento após o orgasmo não sofreu alteração. Ela avalia a relação sexual como sendo boa, mesmo depois de terem passado "por muitas barreiras".

Figura 2: SILVA, R. M. Colagem feita pelo casal. 2007. 1 fotografia.

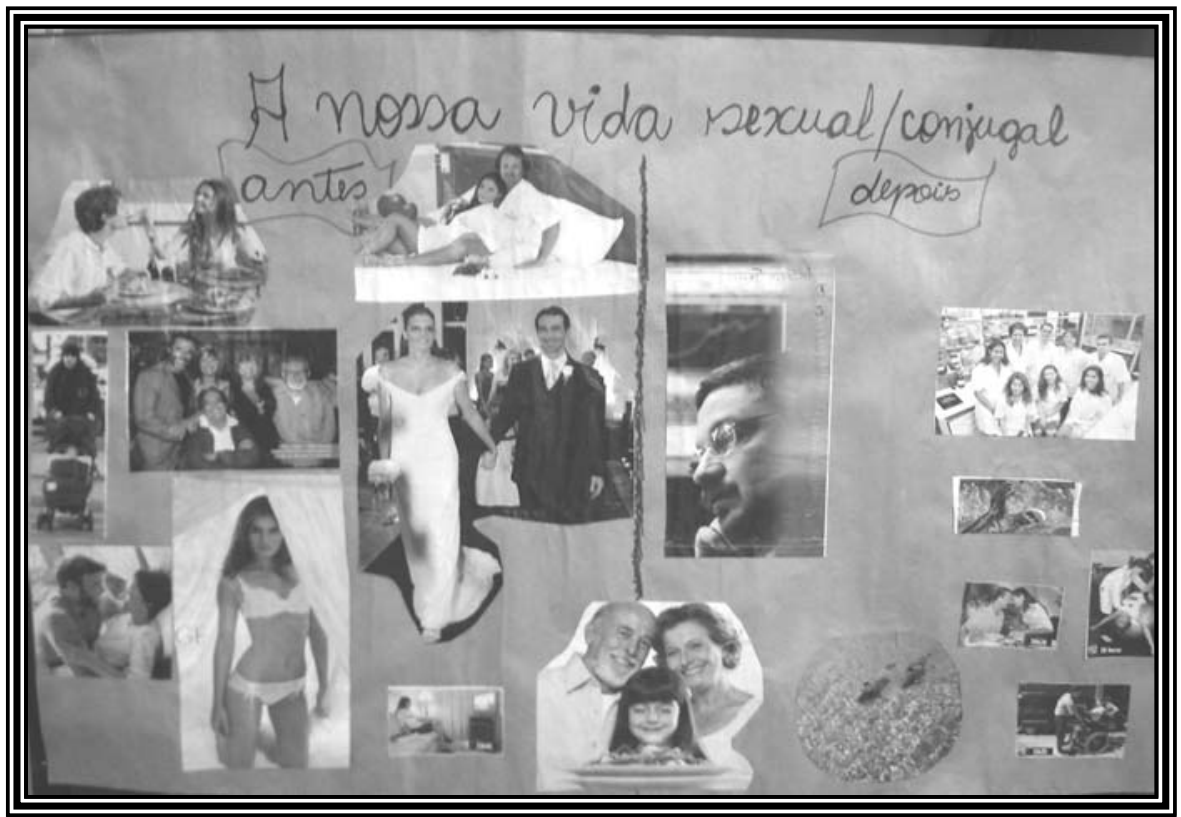

Com relação à colagem (Figura 2), a primeira gravura lembra o início do casamento; os noivos representam a época que se casaram; a mulher que alimenta o homem, o "início da nossa vida conjugal"; a mulher empurrando o carrinho, o nascimento do primeiro filho; a gravura ao lado, um período 
em que o casal se divertia; a imagem do casal se olhando, bons momentos; o homem pensativo representa o recebimento do diagnóstico; a mulher que aparece com roupas íntimas, a liberdade e vaidade do corpo; a mulher sentada no sofá assistindo TV, era o "descanso" de Ivonte quando chegava do trabalho, época em que não tinha filhos; o casal com a criança, o "desejo de envelhecer com saúde, com felicidade" e "o desejo de ter uma neta e cuidar dela"; as duas pessoas nadando, o "prazer do casal em se divertir"; as pessoas de branco, "superando desafios"; a cadeira de rodas lembra a "esperança de estar vivo"; o casal que se olha representa "a ajuda do esposo"; a mulher em tratamento sobre a bola, são os "amigos ajudando em momentos de descontração" e "recuperação plena”; a pessoa nadando sozinha "sou eu, vencendo desafios, lutando por uma vida mais saudável”.

\section{Discussão}

A família de Ivonete e Carlos está vivendo a fase do ciclo de vida que Carter e McGoldrick (2001, p. 17) denominam "lançando os filhos e seguindo em frente", cujas principais tarefas de desenvolvimento são: renegociar o sistema conjugal como díade; desenvolvimento de relacionamentos de adulto-para-adulto entre pais e filhos; realinhamento dos relacionamentos para incluir parentes por afinidade e netos; lidar com incapacidades e morte dos pais (avós). Oliveira e Cerveny (2002) referem-se a essa fase como "família na fase madura", quando acontece uma resignificação da relação conjugal e o casal volta o olhar para o casamento.

Quanto às condições do relacionamento conjugal que facilitam a adaptação a essas novas condiçôes de vida, a família de Ivonete parece possuir papéis e fronteiras flexíveis (MINUCHIN, 1982), mutáveis, quando necessário. O casal conta com forte aliança, uma vez que seus membros lidam com a doença debilitante, com colaboração e satisfação mútua das necessidades, como o fato de Carlos ter deixado o trabalho para ficar à disposição de Ivonete. Assim, Brown (2001) destaca que no caso de doença prolongada a família sofre um estresse permanente em função da incerteza do curso da doença e do medo do momento da morte, podendo ser mais intensificado pelas alterações provocadas pela doença debilitante no sistema familiar.

A elaboração do genograma familiar (Figura 1) é interessante, pois, segundo Carter e McGodrick (2001) fornece dados sobre a repetição de papéis relacionados à família de origem que, no caso de Ivonete e Carlos, mostra que a história de morte por doenças debilitantes é recorrente, bem como os 
cuidados recebidos pelo doente. A infidelidade dos pais de ambos os cônjuges fora do casamento é outra repetição em ambas as famílias de origem, padrão que se repete na vida do casal. Contudo, o câncer de Ivonete traz a perspectiva da fidelidade do esposo, que diz sentir-se feliz com o novo comportamento. A repetição de padrões de educação dos filhos também constitui outro exemplo.

Uma das mudanças ocorridas no padrão sexual após o recebimento do diagnóstico, é que Ivonete diz estar mais “aberta” às questões de sua sexualidade, mostrando-se mais receptiva aos contatos sexuais do esposo. Assim, a doença parece ter proporcionado uma aproximação, ainda maior, entre eles. Masters e Johnson (1988) afirmam que uma mulher, ao sofrer mastectomia sente-se, provavelmente, pouco feminina e incompleta, o que reflete a importância que a sociedade ocidental dá ao seio como símbolo de sexualidade e feminilidade. Apesar disso, algumas mulheres mastectomizadas podem apresentar condutas ativas de sedução e de relacionamento sexual para que possam convencer a si mesmas, bem como a sua parceria sexual, de que continuam sexualmente capazes. Kusnetzoff (1988) afirma que a grande maioria das mulheres enfrenta melhor o problema físico-estético do que o problema emocional e é exatamente este problema que se reflete na área do desempenho sexual, bem como na evolução da doença.

Ivonete considera-se sexualmente tímida por causa da criação recebida. Com a doença, deseja "recuperar o tempo perdido, sem ter que se esconder". Simonton (1990) fala sobre a necessidade da pessoa que está doente de ser acariciada e amada e ressalta a importância da continuidade do contato físico do casal, mesmo sabendo de suas limitações sexuais, sejam elas físicas ou emocionais. Masters e Johnson (1988) acreditam que os quatro tipos de problemas sexuais com os quais as pessoas mais frequentemente se deparam são: a) inibiçōes e remorsos; b) ansiedade pelo desempenho; c) rotina sexual e d) aceitação irracional dos mitos e das informações falsas sobre sexo. Assim, os dados do nosso estudo revelam que a educação sexual recebida pelos participantes, sobretudo pela família de criação de Ivonete, foi muito rigorosa, causando impacto no relacionamento sexual do casal.

A religiāo tem um lugar especial na vida da família de Ivonete e Carlos. Para Pinto (2004, p. 154), "uma das funções da religião é proporcionar às pessoas o sentimento de pertença, um sentimento fundamental na identidade de cada pessoa". Com relação à vida sexual, Ivonete diz sentir-se como se "estivesse pecando", receia estar "agradando" a si mesma e "não a Deus" e pergunta a Ele se é normal que fique com desejo sexual nesse momento da vida. Apesar de mostrar-se resiliente (VASCONCELLOS, 2006) sente-se pecadora pela manifestação de sua sexualidade. 
Com relação à questão da excitação sexual, após o recebimento do diagnóstico, Ivonete acredita que a menopausa causou mais impacto do que o câncer. Isso nos remete a Masters e Johnson (1988), quando afirmam que os níveis de estrogênio, em circulação, sofrem diminuição no período em torno da menopausa, promovendo uma menor lubrificação vaginal durante a fase de excitação sexual. Contudo, no caso de Ivonete, houve a continuidade da excitação sexual, apesar de diminuição de sua intensidade, oriunda de fatores próprios da menopausa e da doença debilitante. $\mathrm{O}$ mesmo ocorreu com o orgasmo.

As relaçōes sexuais de Ivonete e Carlos são realizadas com "delicadeza e cuidado", em função das adaptaçōes nas posiçōes sexuais atuais. Segundo Kusnetzoff (1988), muitas vezes, a parceria teme compartilhar o relacionamento sexual com medo de machucar a pessoa que está com câncer. Isso pode refletir-se, até mesmo, no hábito dos casais que dormem juntos, pois, é possível ocorrer algum dano, quando o cônjuge se mexe ou se vira dormindo, podendo levar a entender que a parceria sexual não quer mais se relacionar com a pessoa que está doente. Com isso, Carlos passou a ter uma resposta sexual mais rápida, o que pode levar à instalação de uma ejaculação precoce pelo condicionamento da ejaculação à resposta sexual rápida. Quando Carlos questiona se Ivonete está realmente interessada ou apenas deseja "cumprir uma obrigação" ou "agradá-lo", pensamos na possibilidade de Ivonete ter desenvolvido anorgasmia. Masters e Johnson (1988, p. 468) afirmam que "algumas mulheres anorgásmicas sentem pouco prazer no sexo e o vêem como uma obrigação do casamento ou meio de manter um relacionamento". Mas, mesmo diante de todas essas dificuldades citadas pelo casal, ambos consideram ter uma boa "relação" sexual, em função de se conhecerem bem e da afetividade recíproca.

\section{Considerações Finais}

Este estudo buscou investigar a repercussão que o câncer de pacientes sob cuidados paliativos tem sobre o relacionamento conjugal e a vida sexual do casal. Enfocamos algumas dimensões do relacionamento familiar e conjugal, como a fase do ciclo de vida e a forma como sistema está se adaptando e se reestruturando para lidar com as novas demandas; o relacionamento do casal com os filhos e outros membros da família; a vida sexual do casal, no período anterior ao recebimento do diagnóstico da doença e atualmente.

Observamos a necessidade de ajustes do sistema familiar, flexibilização de papéis e fronteiras e divisão de responsabilidades, a partir do momento em 
que foi diagnosticada a doença e novas demandas se apresentaram aos membros da família, que se mostraram competentes nessas tarefas.

O casal participante está vivendo um momento de revisão e avaliação do relacionamento conjugal em que a história de vida é repassada em seus detalhes, dando lugar tanto aos momentos de satisfação quanto às mágoas e lembranças de infidelidades. Ivonete mostra-se compreensiva, talvez preocupada em “poupar” o marido, que já sofreu e está sofrendo com a doença da esposa e é tão solícito e dedicado a ela, assumindo seus cuidados com zelo, carinho, atenção e comprometimento. Assim, entendemos por cuidado uma atitude na qual a pessoa sai de si e centra-se no outro, podendo apresentar-se como um dos fatores que leva o esposo, no momento atual, a ser fiel.

O câncer, ainda hoje, com todos os avanços da ciência, continua sendo uma doença com a marca da desesperança, por ainda ser, em muitos casos, debilitante e fatal. Nesse contexto, a religião tem um papel importante no resgate da homeostase do sistema, ao possibilitar o entendimento do que está acontecendo em um nível que transcende a lógica linear e promover esperança de um futuro em condições diferentes.

A doença traz sofrimento e, ao mesmo tempo, "aproximação". Ivonete se diz "mais solta" e à vontade com sua sexualidade e fala em "aproveitar o tempo". Carlos questiona se a esposa "está apenas tentando agradá-lo" quando aceita ter relação sexual, refletindo a instabilidade psicossocial do homem frente às mudanças atuais do comportamento da mulher, em que o domínio e o poder pela sexualidade feminina sofrem alteraçōes mediante uma maior expansão emocional, intelectual, laboral e sexual. Contudo, falar sobre sexualidade parece ter transportado o casal a um momento em que tudo era diferente, cheio de vida, do qual sentem saudade. Ao falar da situação atual, apesar de não desvinculá-la das circunstâncias, também expressam vitalidade. $\mathrm{O}$ desejo de Ivonete em curtir esse tempo de maior abertura, mostra que a doença e seus comprometimentos podem tirar o vigor físico, mas não apagam a chama vital, o desejo de viver e, conseqüentemente, a sexualidade.

Enfocar duas questões aparentemente antagônicas, cuidados paliativos e sexualidade, foi uma experiência importante e acredito que, como pesquisadora, estou mais atenta às questões da complexidade do ser humano. Minha relação com os participantes despertou uma admiração imensa pela força que demonstraram na luta contra a doença debilitante. Assim, fazer este estudo humanizou minha essência pessoal e profissional - como psicóloga e sexóloga. Ao mesmo tempo, ensinou-me que o ser humano possui uma condição que ultrapassa as barreiras de suas limitações diante das adversidades da vida. 


\section{Referências bibliográficas}

ANDOLFI, M.; ÂNGELO, C.; SACCU, C. (Orgs.). O casal em crise. São Paulo: Summus, 1995.

BOURGEOIS-LAW, G.; LOTOCKI, R. Sexuality and gynecological cancer: A needs assessment. The Canadian Journal of Human Sexuality, v. 8, n. 4, p. 231-241, 1999.

BROWN, F. H. O impacto da morte e da doença grave sobre o ciclo de vida familiar. In: CARTER, B.; MCGOLDRICH, M. (Orgs.). As mudanças no ciclo de vida familiar: Uma estrutura para a terapia familiar. Porto Alegre: Artes Médicas, 2001, p. 393-414.

BUCHER, J. S. N. F. O casal e a família sob novas formas de interação. In: FÉRES-CARNEIRO, T. (Org.). Casal e família: Entre a tradição e a transformação. Rio de Janeiro: NAU, 1999, p. 82-95.

CARTER, B.; MCGOLDRICK, M. As Mudanças no ciclo de vida familiar: Uma estrutura para terapia familiar. In: CARTER, B.; MCGOLDRICK, M. (Orgs.). As mudanças no ciclo de vida familiar: Uma estrutura para a terapia familiar. Porto Alegre: Artmed, 2001, p. 7-29.

CASARETT, D. Palliative Care; Palliative care questions unlikely to cause distress for family members. Health \& Medicine Week, p. 1244, 2005. Disponível em: <http:/proquest.umi.com/pqweb?index $=3 \&$ sid= $1 \&$ srchmode $=1 \& v i s n t=$ ROD \&fmt $=3 \&$ clientid $=48429 \& v$ name $=$ PQD\&RQT =309\&did=8(>. Acesso em: 23 jun. 2005.

CAVALCANTI, R.; CAVALCANTI, M. Tratamento clínico das inadequações sexuais. São Paulo: Roca, 1992.

CERQUEIRA, A. A dinâmica conjugal em situação de câncer de mama. Brasília: UCB, 2004.

CERVENY, C. M. O. Pensando a família sistemicamente. In: CEVERNY, C. M. O.; BERTHOUD, C. M. E. (Orgs.). Visitando a família ao longo do ciclo vital. São Paulo: Casa do Psicólogo, 2002, p. 15-27.

CLARKE, P. Men living longer, healthier: Still one thing on their minds. Medical Post, v. 38, n. 46, p. 27, 2002.

DUARTE, T. P.; ANDRADE, A. N. Enfrentando a mastectomia: Análise dos relatos de mulheres mastectomizadas sobre questóes ligadas à sexualidade. Estudos de Psicologia (Natal), v. 8, n. 1, p. 155-163, 2003.

FÉRES-CARNEIRO, T. Família e saúde mental. Psicologia: Teoria e Pesquisa, n. 8, p. 485-493, 1992.

GONZALEZ REY, F.L. Pesquisa qualitativa em psicologia: Caminhos e desafios. São Paulo: Pioneira Thomson Learning, 2005. 
HITE, S. O relatório Hite: Um profundo estudo sobre a sexualidade feminina. 14 ed., São Paulo: Difel, 1982.

HITE, S. O relatório Hite sobre sexualidade masculina. 4 ed., Rio de Janeiro: Bertrand, 1991.

KAPLAN, H.S. A nova terapia do sexo. 6 ed., Rio de Janeiro: Nova Fronteira, 1974.

. Manual ilustrado de terapia sexual. São Paulo: Manole, 1978. . Enciclopédia básica de educação sexual. Rio de Janeiro: Record, 1983.

KINSEY, A.C.; POMEROY, W.B.; MARTIN, C.E. Sexual behavior in the human male. Philadelphia: Saunders, 1948.

KINSEY, A.C.; POMEROY, W.B.; MARTIN, C.E. Sexual behavior in the human female. Philadelphia: Saunders, 1953.

KOLODNY, R.C.; MASTERS, W.; JOHNSON, V. Manual de medicina sexual. São Paulo: Manole, 1982.

KUSNETZOFF, J.C. O homem sexualmente feliz: Do mito à verdade científica. Rio de Janeiro: Nova Fronteira, 1987.

A mulher sexualmente feliz. Rio de Janeiro: Nova Fronteira, 1988.

LEE, H.; ZELEFSKY, M.; MCKEE, A.; LEIBEL, S. Efficacy of oral sildenafil in patients with erectile dysfunction after radiotherapy for carcinoma of the prostate. Urology, n. 53, p. 775-778, 1999.

LIMA, L. M. O traumatismo raquimedular e sua repercussão no relacionamento conjugal. Brasília: UCB, 2005.

MASTERS, W.; JOHNSON, V. A conduta sexual humana. Rio de Janeiro: Civilização Brasileira, 1976.

- A incompetência sexual humana. 3 ed., Rio de Janeiro: Civilização Brasileira, 1979. 1988.

O relacionamento amoroso. Rio de Janeiro: Nova Fronteira,

MCCOUGHLAN, M. A necessidade de cuidados paliativos. In: PESSINI, L.; BERTACHINI, L. (Orgs.). Humanização e cuidados paliativos. 2 ed., São Paulo: Loyola, 2004, p. 167-180).

MCGOLDRICK, M.; GERSON, R. Genetogramas e o ciclo de vida familiar. In: CARTER, B.; MCGOLDRICK, M. (Orgs.). As mudanças no ciclo de vida familiar: Uma estrutura para a terapia familiar. 2 ed., Porto Alegre: Artmed, 2001, p. 144-166.

MINUCHIN, S. Famílias: Funcionamento \& tratamento. Porto Alegre: Artes Médicas, 1982. 
MINUCHIN, S.; FISHMAN, H.C. Técnicas de terapia familiar. Porto Alegre: Artes Médicas, 1990.

MORIN, E. Introdução ao pensamento complexo. 2 ed., Lisboa, Portugal: Instituto Piaget, 1990.

MULLEY, S. Cancer patients want to discuss their sex problems. Medical Post, v. 34, n. 3, p. 21, 1998.

OLIVEIRA, A.L.; CERVENY, C.M.O. Visitando a fase madura. In: CEVERNY, C. M. O.; BERTHOUD, C. M. E. (Orgs.). Visitando a família ao longo do ciclo vital. São Paulo: Casa do Psicólogo, 2002, p. $85-126$.

OSORIO, L.C. \& VALLE, M.E. Dinâmica das relações conjugais: Uma visão contemporânea. In: OSORIO, L.C.; VALLE, M.E. (Orgs.). Terapia de famílias: Novas tendências. Porto Alegre: Artes Médicas, 2002, pp. 9-16.

PANTILAT, S.Z. Heart failure: Palliative care is important for heart failure patients and their families. Heart Disease Weekly, p. 57, 2004.

PAPP, P. Prisioneiros do papel sexual. In: ANDOLFI, M.; ÂNGELO, C.; SACCU, C. (Orgs.). O casal em crise. São Paulo: Summus, 1995, p. $147-154$.

PAYNE, S.; LARGE, S.; JARRETT, N.;TURNER, P. Written information given to patients and families by palliative care units: A national survey. The Lancet, v. 355, n. 9217, p. 1792, 2000.

PESSINI, L. A filosofia dos cuidados paliativos: Uma resposta diante da obstinação terapêutica. In: PESSINI, L.; BERTACHINI, L. (Orgs.). Humanização e cuidados paliativos. 2 ed., São Paulo: Loyola, 2004, p. 181-208.

PINTO, E.B. Reflexões sobre solidariedade, educação e postura de vida. In: HOLANDA, A. (Org.). Psicologia, religiosidade e fenomenologia. Campinas: Alínea, 2004, p. 147-162.

ROLLAND, J. Doença crônica e o ciclo de vida familiar. In: CARTER, B.; MCGOLDRICH, M. (Orgs.). As mudanças no ciclo de vida familiar: Uma estrutura para a terapia familiar. 2 ed., Porto Alegre: Artmed, 2001, p. 373-392.

SATIR, V. A mudança no casal. In: ANDOLFI, M.; ANGELO, C.; SACCU, C. (Orgs.). O casal em crise. São Paulo: Summus, 1995, p. 29-37.

SIMONI, M.; SANTOS, M.L. Considerações sobre cuidado paliativo e trabalho hospitalar: Uma abordagem plural sobre o processo de trabalho de enfermagem. Psicologia USP. v. 14, n. 2, p. 169-194, 2003. 
SILVA, R.M. A sexualidade do casal em situação de cuidados paliativos oncológicos. Brasília: UCB, 2007.

SIMONTON, S.M. A família e a cura: O método Simonton para famílias que enfrentam uma doença. 2 ed., São Paulo: Summus, 1990.

SWIFT, D. Breast cancer survivors want sexuality advice. Medical Post, v. 34, n. 3, p. 35, 1998.

TANG, C.S.; SIU, B.; LAI, F.D.; CHUNG, T.K.H. Heterosexual chinese women's sexual adjustment after gynecologic câncer. The Journal of Sex Research, v. 33, n. 3, p. 189-207, 1996.

TURATO, E. Tratado da metodologia da pesquisa clinico - qualitativa: Construção teórico epistemológica, discussão comparada e aplicação nas áreas de saúde e humanas. Petrópolis, RJ: Vozes, 2003.

VASCONCELLOS, A.C.G.D. O ciclo de vida em famílias com um membro portador de paraplegia: Um estudo sobre resiliência familiar. Brasília: UCB, 2006.

VASCONCELLOS, M.J.E. Terapia familiar sistêmica: Bases cibernéticas. São Paulo: Psy, 1995.

WATZLAWICK, P. Pensamento sistêmico e abordagem dos sistemas humanos. In: ELKAÏM, M. (Org.). Terapia familiar em transformação. São Paulo: Summus, 2000, p. 155-157.

YIN, R. Estudo de caso: Planejamento e métodos. 2 ed., Porto Alegre: Bookman, 2001. 